\title{
LIGHT AS A QUALITY OF MERCY
}

\section{I}

At the end of each short winter day

the dark entered the kitchen

just as the milk came in warm

from the barn. And grandma lighted a lamp

as for some hulking gentle

stranger who had travelled far,

was tired and had little to say.

\section{II}

From Elaine's cupped hand a baby

light is born at the candle tip and you can see its delicate breathing

making friends of the faces around the room.

\section{III}

The switches flip, one-two-three-four, and light leaps out hard as guns to occupy precisely the oblong room.

\section{MOUNTAINS}

This quiet of mountains whispering to mountains could demand your complete disappearance in the most blatant sunlight.

Winds shake their heads, they'll have nothing to do with these trees, not even the tallest.

A road ancient as Abraham's cattle leads your fifty-miles-an-hour on and on and says nothing.

Although ear and eye may swivel in every primitive direction, they will not detect anything at all

because events happen here like unimaginable sculptures, neutral, to one side or the other of every place there is

and they keep no time small enough for clock-towers.

The stillness among mountains has no right whatever.

It may be only the subtlest bones in your own head vibrating. 